\title{
Calcific Tendinitis of the Longus Colli
}

\author{
Daiji Uchiyama ${ }^{1}$, Katsumi Nakamura ${ }^{1}$, Seigo Yoshida ${ }^{1}$ and Kenji Shimizu ${ }^{2}$
}

Key words: calcific tendinitis of the longus colli, abscess, neck pain, calcification

(Intern Med 55: 553, 2016)

(DOI: 10.2169/internalmedicine.55.5846)

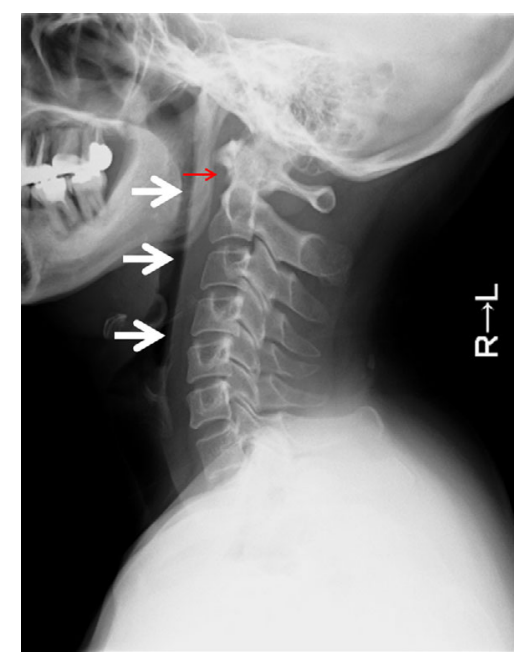

Picture 1.

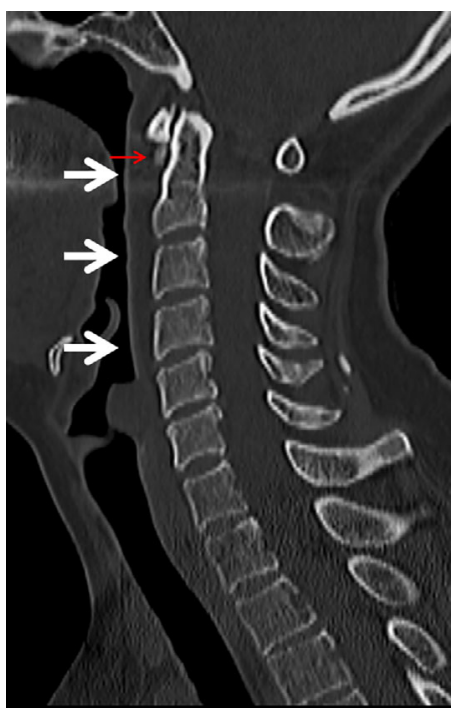

Picture 3.

A 47-year-old woman presented with severe neck pain and stiffness associated with dysphagia. The laboratory data

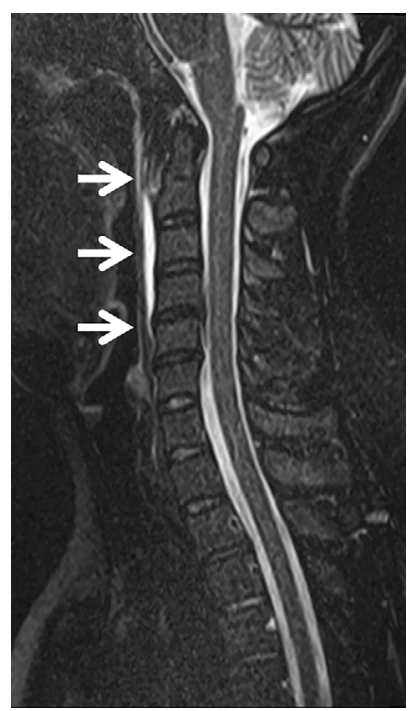

Picture 2.

showed slight leukocytosis of $10,680 / \mu \mathrm{L}$ and slight elevation of C-reactive protein. The findings of a lateral radiograph, computed tomography (CT), and magnetic resonance imaging (MRI) demonstrated calcification in front of the axis (Picture 1, 3. red arrows) and swelling of the prevertebral soft tissue from C1 to C5 (Picture 1-3. white arrows). We diagnosed the lesion to be calcific tendinitis of the longus colli and treated her with a non-steroidal anti-inflammatory drug. Two weeks later, the symptoms, prevertebral soft tissue swelling, and calcium deposition almost completely disappeared.

Although calcific tendinitis of the longus colli is rare, physicians must keep in mind the possibility of this disease, as retropharyngeal abscesses and infectious spondylitis present with very similar symptoms and imaging findings. CT and MRI are useful in both the detection and differential diagnosis of longus colli muscle abnormalities.

The authors state that they have no Conflict of Interest (COI).

\footnotetext{
${ }^{1}$ Department of Radiology, Tobata Kyoritsu Hospital, Japan and ${ }^{2}$ Department of Orthopedics, Tobata Kyoritsu Hospital, Japan Received for publication May 29, 2015; Accepted for publication June 8, 2015

Correspondence to Dr. Daiji Uchiyama, uchiyama.daiji@gmail.com

(C) 2016 The Japanese Society of Internal Medicine Journal Website: http://www.naika.or.jp/imonline/index.html
} 